\title{
PERSEPSI MASYARAKAT TERHADAP KEUNIKAN ALAM DANAU BATUR, BALI
}

\author{
Riyawati Ika Dewi \\ Manajemen Lingkungan S2 Pascasarjana UNJ, email: mamadzaky02@gmail.com
}

\begin{abstract}
Abstrak
Penelitian ini bertujuan untuk mendapatkan informasi tentang persepsi masyarakat tentang pengaruh pembangunan insfrastruktur penunjang Danau Batur terhadap keunikan alam Danau batur, di Kecamatan Kintamani, Kabupaten Bangli Provinsi Bali. Penelitian ini menggunakan metode survey dengan pendekatan kuantitatif deskriptif. Pengumpulan data menggunakan teknik kuesioner. Teknik analisis data yang digunakan adalah uji persyaratan analisis, analisis regresi linier sederhana dengan sampel sebanyak 20 orang (10 orang wanita dan 10 orang pria). Hasilnya adalah pembangunan infrastruktur penunjang yang dilaksanakan di Objek wisata ekowisata Danau batur selaras dengan keuinikan alam dari Danau Batur. Hal ini dapat dilihat dari pendapat dan persepsi pengunjung yang mengatakan bahwa keunikan alam Danau Batur tetap terjaga dan tetap bisa dinikmati dari dulu hingga sekarang.
\end{abstract}

Kata Kunci : Persepsi masyarakat, keunikan alam, Danau Batur

\begin{abstract}
This study aims to obtain information about public perceptions about the effect of the development of supporting infrastructure of Lake Batur on the natural uniqueness of Lake Batur, in Kintamani District, Bangli Regency, Bali Province. This research uses survey method with descriptive quantitative approach. Data collection using a questionnaire technique. The data analysis technique used is the requirements analysis test, simple linear regression analysis with a sample of 20 people (10 women and 10 men). The result is the development of supporting infrastructure carried out in Lake Batur ecotourism attractions in harmony with the natural beauty of Lake Batur. This can be seen from the opinions and perceptions of visitors who say that the natural uniqueness of Lake Batur is maintained and can still be enjoyed from the past until now.
\end{abstract}

Keywords: Community perception, natural uniqueness, Lake Batur 


\section{PENDAHULUAN}

Menurut paparan Paparan Deputi Bidang Pengembangan Destinasi dan Investasi Pariwisata Kementrian Pariwisata, 2016 untuk kunjungan wisatawan ke Indonesia ada 3 jenis produk yang diminati yaitu Alam (nature) 35\%, Budaya (Culture) 60\% dan Buatan Manusia (Man Made) 5\%. Danau Batur adalah produk untuk objek wisata yang menggabungkan antara produk alam dan produk budaya. Satu hal yang tidak lepas dari adanya Gunung Batur adalah Danau Batur. Danau Batur yang terletak di Kecamatan Kitamani, Kabupaten Bangli, merupakan danau terbesar di Pulau Bali. Data potensi sumberdaya alam pada suatu ekosistem gunungapi secara utuh dan menyeluruh penting diketahui sebagai dasar untuk membuat perencanaan pembangunan yang berkesinambungan.

Lokasi sekitar Danau Batur memiliki beragam kondisi topografi dengan tingkat kemiringan berkisar antara 0 sampai dengan 25\%, 25 sampai dengan $40 \%$ dan lebih dari $40 \%$. Selain itu berdasarkan ketinggian dari permukaan air laut, Danau Batur terletak antara $1000 \mathrm{~m}$ di atas permukaan laut. Dataran tertinggi terletak antara 3000m 4000m diatas permukaan air laut. Luas permukaan danau mencapai 16,05 $\mathrm{km}$ dengan luas daerah tangkapan menurut hitungan pada peta Bakosurtanal sebesar 102,50 km (Dinas PU Prov.Bali dalam
Pengelolaan Ekosistem Danau Batur oleh Pusat Pengendalian Pembangunan Ekoregion Bali dan Nusa Tenggara).

Menurut paparan Paparan Deputi Bidang Pengembangan Destinasi dan Investasi Pariwisata Kementrian Pariwisata, 2016 untuk kunjungan wisatawan ke Indonesia ada 3 jenis produk yang diminati yaitu Alam (nature) 35\%, Budaya (Culture) $60 \%$ dan Buatan Manusia (Man Made) 5\%. Danau Batur adalah produk untuk objek wisata yang menggabungkan antara produk alam dan produk budaya. Menurut sejarahnya, asal muasal Danau Batur berasal dari Gunung Batur. Ekosistem gunung api merupakan salah satu bentuk ekosistem yang ada di dunia. Indonesia adalah negara yang paling banyak (128 buah yang aktif) mempunyai gunung api di dunia,tiga di antaranya terdapat di propinsi Bali (Gunung Batur, Gunung Agung, Gunung Batukaru). Masyarakat umumnya menganggap bahwa wilayah gunungapi itu memiliki kesuburan tanah yang tinggi, berpenduduk padat, tetapi sering dihadapkan pada resiko bencana alam yang ditimbulkan, seperti erupsi gunungapi, aliran lahar panas maupun lahar dingin, dan longsor lahan. Informasi yang diketahui masyarakat tentang gunungapi kebanyakan adalah tingkat bahayanya. Data potensi sumberdaya alam pada suatu ekosistem gunungapi secara utuh dan menyeluruh 
penting diketahui sebagai dasar untuk membuat perencanaan pembangunan yang berkesinambungan. Gunung Batur selama ini dikenal masyarakat umum sebagai salah satu obyek tujuan wisata dengan memanfaatkan keindahan panorama alam sebagai daya tariknya. Namun demikian, potensi sumberdaya alam yang tersedia di wilayah gunungapi Batur sebagai satu satuan ekosistem belum diketahui secara rinci. Kenyataan tersebut menjadikan daya dukung lingkungann di wilayah gunung Baturpun belum diketahui.

Satu hal yang tidak lepas dari adanya Gunung Batur adalah Danau Batur. Danau Batur yang terletak di Kecamatan Kitamani, Kabupaten Bangli, merupakan danau terbesar di Pulau Bali. Danau ini menjadi tumpuan utama secara alami sebagai cadangan air untuk Bali serta keberadaannya menciptakan ekosistem spesifik di sekitarnya untuk menjaga keberlangsungan daur hidrologi bagi Bali secara keseluruhan. Danau Batur merupakan salah satu dari 15 (limabelas) danau yang menjadi prioritas pemulihan kerusakan danau di Indonesia berdasarkan kesepakatan Bali tahun 2009 tentang pengelolaan danau berkelanjutan. Kesepakatan tersebut dideklarasikan atas keprihatinan kondisi ekosistem danau di Indonesia yang semakin terancam akibat kerusakan dan pencemaran lingkungan pada daerah tangkapan air (DTA) hingga perairan danaunya.
DOI : doi.org/10.21009/jgg.091.03

Sebagai suatu sistem sumber daya air, perairan ekosistem Danau Batur mengandung potensi sumberdaya hayati dan non hayati yang belum terdata dan terinventarisasi secara memadai dalam rangka pendayagunaan bagi pengembangan aktivitas pertanian dan perikanan perairan umum. Pengembangan pertanian dan perikanan Danau Batur mempunyai arti yang strategis dalam rangka pemberdayaan ekonomi masyarakat sekitar danau, pelestarian keanekaragaman hayati dan pengembangan pariwisata.

Masyarakat yang hidup pada daerah wisata sangat mengerti akan adanya hal yang akan membuat keunikan alam daerah tersebut menjadi kurang (Kustawa, G.K, 2012). Selain itu banyak aktivitas yang dilakukan oleh masyarakat bali (khususnya yang tinggal di sekitar Danau Batur) yang memanfaatkan danau batur sebagai salah satu sumber air dan sumber kehidupannya. Sumber air adalah untuk keiatan domestic keseharian masyarakat dan sumber kehidupan adalah dengan aktivitas pariwisatanya.

Pariwisata yang dilakukan adalah wisata alam dan wisata budaya. Akibat adanya aktivitas tersebut tanpa adanya pengelolaan yang baik dan ramah lingkungan menyebabkan terjadinya berbagai permasalahan di Danau Batur. Permasalahan mendasar mengenai penyelamatan keanekaragaman hayati di Indonesia adalah 
masih kurangnya peran masyarakat terhadap aktifitas penyelamatan kekayaan alam Indonesia itu sendiri (Hotimah, Oot 2015). Adapun permasalahan yang dapat diindentifikasi oleh pihak "Pusat Pengendalian Pembangunan Ekoregion Bali dan Nusa Tenggara, Kementrian Lingkungan Hidup dan kehutanan R.I tahun 2015) adalah sebagai berikut :

1. Kerusakan dan penyempitan areal hutan

2. Alih Fungsi Lahan

3. Erosi dan Sedimentasi

4. Pencemaran air danau

5. Pemanfaatan air yang berlebihan

6. Eutrofikasi

Masalah-masalah tersebut sebagai salah satu indikasi jika Daya dukung lingkungan Danau Batur telah menurun.

Melihat kondisi ini Perintah Provinsi Bali berkoordinasi dengan Kementrian Lingkungan Hidup dan kehutanan untuk membuat cara untuk menaggulanginya sesuai dengan pedoman yang terdapat pada Undang-Undang No. 32 Tahun 2009 dan Peraturan Menteri Lingkungan Hidup No. 17 Tahun 2009. Hal ini semakin gencar dan kuat dilakukan setelah Danau Batur merupakan salah satu dari 15 (limabelas) danau yang menjadi prioritas pemulihan kerusakan danau di Indonesia berdasarkan kesepakatan Bali tahun 2009 tentang pengelolaan danau berkelanjutan untuk periode 2010-2014
DOI : doi.org/10.21009/jgg.091.03

Kebijakan dan strategi Provinsi Bali dalam pengembangan kawasan strategis adalah :

1. Pelestarian dan peningkatan fungsi dan daya dukung lingkungan hidup

2. Pengembangan dan peningkatan fungsi kawasan dalam pengembangan perekonomian provinsi yang produktif, efisien, dan mampu bersaing dalam perekonomian nasional dan internasional

3. Pelestarian dan peningkatan nilai sosial budaya daerah Bali

Dalam pengelolaan ekosistem danau Batur beberapa program yang dicanangkan oleh pemerintah provinsi Bali adalah :

1. Masterplan Pengelolaan Ekosistem Danau Batur.

2. RADT Pengelolaan Ekosistem Danau Batur.

3. Kajian Daya Tampung Beban Pencemaran Danau Batur.

4. Grand Design Gerakan Penyelamatan Danau (Germadan) Batur.

5. Kebijakan pemerintah daerah dalam pengelolaan Danau Batur tertuang di dalam RTRW Kabupaten

(Sumber Gerakan Penyelamatan Danau Batur, KLHK 2014) 
Jumlah wanita : 10 orang

Rentang umur : $<25$ tahun

\section{METODOLOGI}

Penelitian dilakukan di Danau Batur, Kecamatan Kintamani Kabupaten Bangli pada tanggal 12 Mei 2018. Alat dan bahan yang diperlukan adalah lembar kuesioner dan kamera sebagai alat dokumentasi. Narasumber untuk adalah wisatawan yang datang berkunjung ke kawasan objek wisata Danau Batur dan petugas pengelola kawasan. Penentuan sampel dilakukan secara acak proporsional antara responden pria dan wanita. Dalam penelitian ini dipilih 10 orang responden pria dan 10 orang responden wanita. Penelitian dilakukan dengan teknik wawancara semi tersktuktur berpedoman kuesioner, pengamatan lapangan, dan kajian literatur untuk melengkapi data yang dibutuhkan. Variabel yang menjadi atribut penelitian ini adalah dukungan sosial yaitu penilaian masyarakat atas keunikan danau batur dan upaya dilakukan oleh pengelola kawasan untuk menjaga keunikan dan kesrian alam Objek wisata Danau Batur (sebagai salah satu cara pengelolaan yang berkelanjutan)

\section{HASIL DAN PEMBAHASAN}

Data dan informasi yang diperoleh dianalisis secara deskriptif kuantitatif dan didapat data sebagai berikut :

Jumlah Responden : 20 0rang

Jumlah Pria : 10 orang
Tabel 1. Informasi data

\begin{tabular}{|c|c|c|c|c|c|}
\hline \multirow{3}{*}{$\mathrm{No}$} & \multirow{3}{*}{ Deskripsi } & \multicolumn{4}{|c|}{ Responden } \\
\hline & & \multicolumn{2}{|c|}{ Pria } & \multicolumn{2}{|c|}{ Wanita } \\
\hline & & $\mathrm{Ya}$ & Tidak & $\mathrm{Ya}$ & Tidak \\
\hline 1 & $\begin{array}{l}\text { Didampingi } \\
\text { oleh guide }\end{array}$ & $50 \%$ & $50 \%$ & $0 \%$ & $\begin{array}{l}100 \\
\%\end{array}$ \\
\hline 2 & $\begin{array}{l}\text { Unik } \\
\text { Suasananya } \\
\text { dan } \\
\text { memberika } \\
\text { n kesan }\end{array}$ & $100 \%$ & $0 \%$ & $100 \%$ & $0 \%$ \\
\hline 3 & $\begin{array}{l}\text { Keunikanny } \\
\text { a tidak } \\
\text { ditemukan } \\
\text { didaerah } \\
\text { lain } \\
\end{array}$ & $100 \%$ & $0 \%$ & $100 \%$ & $0 \%$ \\
\hline 4 & $\begin{array}{l}\text { Indah dana } \\
\text { sri suasanya }\end{array}$ & $100 \%$ & $0 \%$ & $100 \%$ & $0 \%$ \\
\hline 5 & $\begin{array}{l}\text { Dapat } \\
\text { dinikmati } \\
\text { setiap saat }\end{array}$ & $100 \%$ & $0 \%$ & $60 \%$ & $40 \%$ \\
\hline 6 & $\begin{array}{l}\text { Danau } \\
\text { Batur } \\
\text { merupakan } \\
\text { hasil alam }\end{array}$ & $100 \%$ & $0 \%$ & $100 \%$ & $0 \%$ \\
\hline 7 & $\begin{array}{l}\text { Akses jalan } \\
\text { mudah dan } \\
\text { nyaman }\end{array}$ & $100 \%$ & $0 \%$ & $60 \%$ & $40 \%$ \\
\hline 8 & $\begin{array}{l}\text { Flora } \\
\text { terjaga } \\
\text { keunikan } \\
\text { dan } \\
\text { keasrian } \\
\end{array}$ & $100 \%$ & $0 \%$ & $100 \%$ & $0 \%$ \\
\hline 9 & $\begin{array}{l}\text { Flora nya } \\
\text { tidak } \\
\text { ditemukan } \\
\text { didaerah } \\
\text { lain } \\
\end{array}$ & $0 \%$ & $100 \%$ & $0 \%$ & $100 \%$ \\
\hline 10 & \begin{tabular}{l|} 
Flora \\
khusus
\end{tabular} & $0 \%$ & $100 \%$ & $0 \%$ & $100 \%$ \\
\hline 11 & $\begin{array}{l}\text { pengunjung } \\
\text { menggangu } \\
\text { keasrian } \\
\text { flora }\end{array}$ & $0 \%$ & $100 \%$ & $0 \%$ & $100 \%$ \\
\hline 12 & $\begin{array}{l}\text { Fauna } \\
\text { terjaga } \\
\text { keunikan } \\
\text { dan } \\
\text { keasrian } \\
\end{array}$ & $0 \%$ & $100 \%$ & $0 \%$ & $100 \%$ \\
\hline 13 & $\begin{array}{l}\text { Fauna nya } \\
\text { tidak } \\
\text { ditemukan } \\
\text { didaerah } \\
\text { lain } \\
\end{array}$ & $0 \%$ & $100 \%$ & $0 \%$ & $100 \%$ \\
\hline 14 & $\begin{array}{l}\text { Fauna } \\
\text { khusus }\end{array}$ & $0 \%$ & $100 \%$ & $0 \%$ & $100 \%$ \\
\hline 15 & $\begin{array}{l}\text { Ada tanda } \\
\text { khusus agar } \\
\text { menjaga } \\
\text { lingkungan } \\
\text { danau batur }\end{array}$ & $80 \%$ & $20 \%$ & $80 \%$ & $20 \%$ \\
\hline
\end{tabular}




\begin{tabular}{|c|l|l|l|l|l|}
\hline 16 & $\begin{array}{l}\text { Kebersihan } \\
\text { danau batur } \\
\text { terjaga }\end{array}$ & $100 \%$ & $0 \%$ & $100 \%$ & $0 \%$ \\
\hline 17 & $\begin{array}{l}\text { Toilet } \\
\text { cukup }\end{array}$ & $100 \%$ & $0 \%$ & $50 \%$ & $50 \%$ \\
\hline 18 & $\begin{array}{l}\text { Tempat } \\
\text { sampah } \\
\text { cukup }\end{array}$ & $70 \%$ & $30 \%$ & $50 \%$ & $50 \%$ \\
\hline 19 & $\begin{array}{l}\text { Tempat } \\
\text { samaph } \\
\text { yang } \\
\text { disediakan } \\
\text { terpilah }\end{array}$ & $0 \%$ & $100 \%$ & $0 \%$ & $100 \%$ \\
\hline 20 & $\begin{array}{l}\text { Penjual } \\
\text { makanan } \\
\text { dilokasi } \\
\text { yang } \\
\text { terpusat dan } \\
\text { terkumpul }\end{array}$ & $100 \%$ & $0 \%$ & $100 \%$ & $0 \%$ \\
\hline 21 & $\begin{array}{l}\text { Pengunjung } \\
\text { terinformasi } \\
\text { kan waktu } \\
\text { kunjungan } \\
\text { lokasi } \\
\text { wisata }\end{array}$ & $0 \%$ & $100 \%$ & $0 \%$ & $100 \%$ \\
\hline 22 & $\begin{array}{l}\text { Pengunjung } \\
\text { terinformasi } \\
\text { kan hari } \\
\text { libur lokasi } \\
\text { wisata }\end{array}$ & $0 \%$ & $100 \%$ & $0 \%$ & $100 \%$ \\
\hline 23 & $\begin{array}{l}\text { Sarana dan } \\
\text { prasarana } \\
\text { penunjang } \\
\text { dapat } \\
\text { berintegrasi } \\
\text { dan } \\
\text { menjaga } \\
\text { keunikanny } \\
\text { a }\end{array}$ & $100 \%$ & $0 \%$ & $100 \%$ & $0 \%$ \\
\hline
\end{tabular}

Keunikan menurut kamus besar bahasa Indonesia adalah : Nomina (kata benda) sifat (keadaan, hal) unik; kekhususan; keistimewaan: berbagai keunikan di daerah ini akan dijumpai. Perasaan unik, istimewa, khusus mengacu pada persepsi masing-masing orang yang melihatnya. Persepsi menurut menurut kamus besar bahasa Indonesia adalah : 1 tanggapan (penerimaan) langsung dari sesuatu; serapan: 2 proses seseorang mengetahui beberapa hal melalui pancaindranya. Sementara menurut Robbins
(2003) persepsi merupakan sebuah proses yang ditempuh masing-masing individu untuk mengorganisasikan serta menafsirkan kesan dari indera yang anda miliki agar memberikan makna kepada lingkungan sekitar. Banyak faktor-faktor yang dapat mempengaruhi sebuah persepsi, mulai dari pelaku persepsi, objek yang dipersepsikan serta situasi yang ada. Dikarenakan Danau Batur adalah Danau bentukan alam yang bersifat alamiah, maka salah satu faktor keuinikan yang dijadikan faktor penentu adalah adanya Flora dan Fauna endemik, serta persepsi dari masing-masing personal individu.

Dari hasil tabel di atas dapat dilihat jika jumlah pengunjung Danau Batur mayoritas adalah wisatawan lokal yang tidak didampingi oleh guide. Mereka mengunjungi Danau batur lebih karena ingin menikmati susasana yang asri dan alamiah. Meskipun (ternyata) flora dan fauna yang endemik di daerah Danau Batur tidak spesifik dan khusus tetapi yang diminati sebagai keunikan Danau Batur adalah suasana alamnya yang menyatu antara keasrian alam, kehidupan sosial masyarakat dan kehidupan agamais masyarakatnya. Pura disebut sebagai salah satu hal yang menarik minat para pengunjung untuk datang.

Secara keseluruhan pengelola kawasan Danau batur telah berusaha untuk membuat fasilitas pendukung yang tidak menghilangkan ciri khas dan keunikan 
Danau batur. Para pedagang dan pusat oleholeh di berikan lokasi yang terpadu, guna menghindari pembuanga sampah yang tidak terkontrol. Meskipun para pengunjung merasa penyediaan tong sampah masih kurang, tetapi kesadaran para pengunjung untuk tidak membuang sampah sembarangan bisa membantu untuk menjaga kebersihan Danau Batur. Penyediaan toilet menjadi salah satu hal yang dirasa kurang. Khususnya bagi para pengunjung wanita. Hal ini dapat dipahami dikarenakan wanita membutuhkan waktu lebih lama di toilet. Jadi dengan jumlah yang minim akan mengakibatkan antrian pada saat akan ke toilet. Jalan akses yang dirasa gelap dan berliku juga menjadi hal yang dirasa kurang sempurna. Khususnya bagi wisatawan wanita, sebab akses yang dilalui hanya sempurna bagi pengendara motor, sementara wanita banyak yang tidak mampu untuk mengendarai motor.

Hal yang tidak dipahami oleh semua responden adalah waktu kunjungan dan hari libur kawasan Danau batur. Ternyata pengelola kawasan Danau batur tidak menerapkan waktu operasional dan waktu hari libur untuk kawasan tersebut. Operasional Danau Batur adalah 24 jam dan tidak ada hari libur. Padahal hari libur dan pembatasan kunjungan akan membuat pengelola memiliki waktu yang lebih banyak untuk mengatur dan membersihkan lokasi tersebut. Dilain sisi dapat membuat
DOI : doi.org/10.21009/jgg.091.03

flora dan fauna yang ada rileks dan istirahat dari gangguan pengunjung.

\section{KESIMPULAN}

Dari hasil yang pengumpulan data dengan sistem kusioner didapat hasil jika pengelolaan lingkungan Danau Batur telah memiliki prinsip prinsip berwawasan lingkungan dan berkelanjutan. Parameterparameter untuk menjaga keasrian dan keunikan Danau batur telah dilakukan oleh pihak pengelola kawasan. Hanya waktu perawatan dan waktu istirahat bagi flora dan fauna untuk rileks dari gangguan pengunjung belum menjadi faktor yang diperhatikan dan perlu diterapkan.

Para wisatawan pun sangat menyetujui jika keunikan Danau Batur tetap terjaga dan tetap bisa dinikmati dan dirasakan hingga saat ini. Meskipun beberapa penelitian mengindikasikan jika daya dukung lingkungan Danau Batur telah menurun, tetapi wisatawan pengunjung tidak merasakannya. Hal yang dirasakan kurang nyaman hanyalah jalan menuju lokasi Danau Batur, Jumlah toilet dan jumlah tong sampah. Ketidakpuasan itupun tidak 100\% diungkapkan oleh wisatawan pengunjung. Masih ada wisatawan pengunjung yang puas dengan fasilitas dan insfrastruktur yang disediakan oleh pengelola kawasan. Nilai kepuasan ini dikarenakan adanya sinkronisasi antara fasilitas penunjang yang dibangun dengan keunikan alam yang 
dimiliki Danau Batur. Fasilitas tambahan tidak sedikitpun mengurangi keunikan alam Danau batur

\section{DAFTAR PUSTAKA}

Brown Katrina, et all Tourism and Sustainabality in Environmetally Fragile Areas : Case Studies From The Maldives, Nepal researchgate/publication/231975072, ISSN 0967-8875

Danu Wijaya, et all, Kajian kualitas perairan dan potensi produksi sumber daya ikan di danau batur, BALI, Balai Penelitian Pemulihan dan Konservasi Sumber Daya Ikan

Gerakan Penyelamatan Danau Batur (Germadan),2014.Kementrian

Lingkungan Hidup Republik Indonesia, pdf

Gusti, Gede Kustawa Issues on Bali Tourism Development and Community Empowerment to Support Sustainable Tourism Development, Elsevier, 4 ( 2012 ) 413 - 422

H.S Hengky, Gazing Coastal Ecotourism in Morotai Islands, Indonesia, Environmental Management and Sustainable Development, 2017, Vol. 6, No. 2, ISSN 2164-7682

Hotimah, Oot, Partisipasi Masyarakat dalam Pelestarian Hutan Kota, SPATIALWahana Komunikasi dan Informasi Geografi, Vol 13 No. 1 Maret 2015
Hotimah, Oot et all, Conservation of world heritage botanical garden in an environmental frendly city, El sevier 28, (2015) 453-463

Kajian daya dukung lingkungan hidup Danau Batur, Bali oleh Pusat Pengendalian Pembangunan Ekoregion Bali dan Nusa Tenggara, Kementrian Lingkungan Hidup dan kehutanan R.I tahun 2015

Pengelolaan Ekosistem Danau Batur, (HTTP://PPEBALINUSRA.MENLH. GO.ID), Kementrian Lingkungan Hidup dan Kehutanan Republik Indonesia

Paparan Deputi Bidang Pengembangan Destinasi dan Investasi Pariwisata Kementrian Pariwisata, Pembangunan Destinasi Pariwisata Prioritas 20162019, pdf

Peraturan Menteri Lingkungan Hidup No. 17 Tahun 2009 Tentang Pedoman Penentuan Daya Dukung Lingkungan Hidup dalam Penataan Ruang

Saputra Gian, Respon Wisatawan terhadap Pengembangan Batur Global Park, JUMPA 2 [2] : 77 - 94, ISSN 24069116

Tangian, Diane et all, Model of Ecotourism Management in Small Islands of Bunaken National Park, North Sulawesi, Journal of Indonesian Tourism and Development Studies, EISSN : 2338-1647

$\begin{array}{ccr}\text { Undang-undang } & 32 / 2009 & \text { tentang } \\ \text { Perlindungan } & \text { dan } & \text { Pengelolaan } \\ \text { Lingkungan } & & \end{array}$

